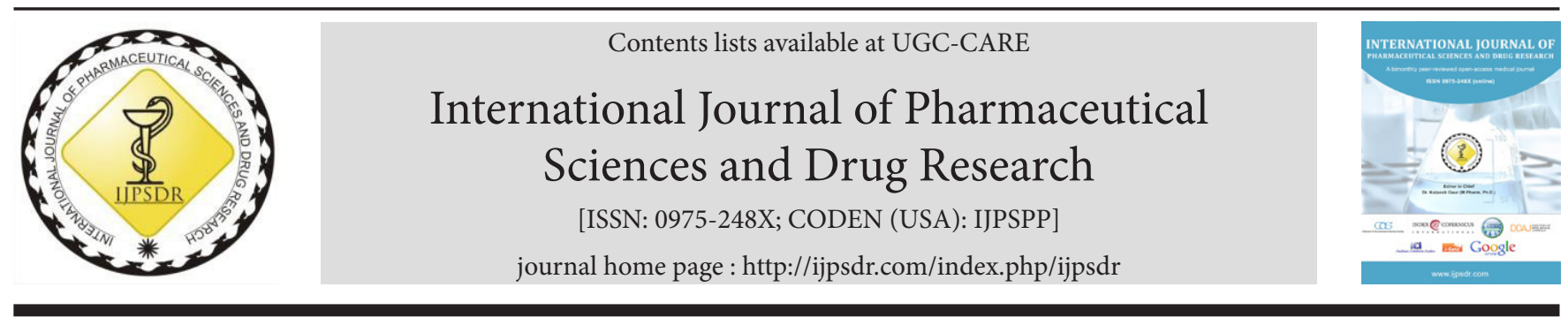

Research Article

\title{
Protective Effect of Barringtonia racemosa Ethyl Acetate Fraction against Cisplatin-Induced Nephrotoxicity in Rats
}

\author{
Rachna B. Patel ${ }^{1}$, Umesh B. Mahajan ${ }^{1}$, Sameer N. Goyal ${ }^{2}$, Sanjay J. Surana ${ }^{3}$, Chandragouda R. Patil ${ }^{1}$, \\ Kalpesh R. Patil ${ }^{1 *}$ \\ ${ }^{1}$ Department of Pharmacology, R. C. Patel Institute of Pharmaceutical Education and Research, Shirpur-425405, District Dhule, Maharashtra, India \\ ${ }^{2}$ Shri Vile Parle Kelavani Mandal's Institute of Pharmacy, Dhule-424001, Maharashtra, India \\ ${ }^{3}$ Department of Pharmacognosy, R. C. Patel Institute of Pharmaceutical Education and Research, Shirpur-425405, District Dhule, Maharashtra, India
}

\begin{tabular}{|c|c|}
\hline A R T I C L E I N F O & A B S T R A C T \\
\hline Article history: & Cisplatin is a major antineoplastic drug for the treatment of solid tumors. Nephrotoxicity is a dose- \\
\hline Received: 28 April, 2020 & limiting side effect associated with the clinical use of cisplatin. The present study was executed to \\
\hline Revised: 06 June, 2020 & determine whether bartogenic acid, containing fraction of Barringtonia racemosa fruits (BREAF) possess \\
\hline Accepted: 26 Iune & a nephroprotective effect against cisplatin-induced nephrotoxicity in rats. Furthermore, the study was also \\
\hline Асcерted: zo junt & aimed to explore the mechanisms underlying this effect of BREAF. The BREAF was orally administered at \\
\hline Published: 30 July, 2020 & the doses of $(2,5$, and $10 \mathrm{mg} / \mathrm{kg})$ for five consecutive days following single-dose administration of cisplatin \\
\hline Keywords: & ( $5 \mathrm{mg} / \mathrm{kg}$, i.p.). Treatment of animals with cisplatin resulted in significant body weight changes, oxidative \\
\hline Anti-oxidant, & stress, elevated levels of serum biomarkers, and histological alterations in the kidney architecture. The \\
\hline Barrinatonia & BREAF administration reduced relative body weight and organ weight changes in cisplatin-treated rats. \\
\hline 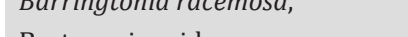 & The BREAF exhibited a nephroprotective effect through the significant reduction of the cisplatin-induced \\
\hline Bartogenic acid, & rise in the serum creatinine and blood urea nitrogen levels, as well as, renal levels of malondialdehyde \\
\hline Cisplatin, & (MDA) the makers of lipid peroxidation. Additionally, the treatment with BREAF resulted in increased renal \\
\hline Nephrotoxicity. & levels of reduced glutathione (GSH), superoxide dismutase (SOD), and catalase activity. Histopathological \\
\hline DOI: & examination established the nephroprotective effect of BREAF. In conclusion, the anti-oxidant and \\
\hline 10.25004/IJPSDR. & anti-inflammatory effects of BREAF have an important role underlying its nephroprotective effect. \\
\hline
\end{tabular}

\section{INTRODUCTION}

Cisplatin is a platinum compound and chemotherapeutic agent effective against wide variety of cancer. ${ }^{[1,2]}$ Although higher doses of cisplatin suppress cancer, chemotherapy with cisplatin is associated with various organ toxicities. ${ }^{[2]}$ Cisplatin-induced nephrotoxicity is a limiting factor in the clinical use of this potential chemotherapeutic agent. ${ }^{[3,4]}$ Drug-induced nephrotoxicity is an extremely common condition that is responsible for a variety of pathological effects on the kidneys. Nephrotoxicity refers to characteristics of structural and functional abnormalities in the renal structures that occur in patients following exposure to the toxicants. ${ }^{[5]}$
Acute renal failure has been reported after a single dose of cisplatin. ${ }^{[4,6]}$ Cisplatin accumulates in the proximal and distal convoluted tubules and promotes the kidney damage. Renal impairment is manifested by increased serum creatinine and blood urea nitrogen levels. ${ }^{[3,7]}$ Several mechanisms, like DNA damage, oxidative stress, apoptosis, and inflammation are involved in cisplatininduced nephrotoxicity. ${ }^{[4,8,9]}$

Cisplatin targets the proximal tubule and decreases the glomerular filtration rate and causes subsequent renal failure. ${ }^{[10]}$ Anti-oxidants like GSH, SOD, and catalase (CAT) help to scavenge the reactive oxygen species (ROS). Anticancer drug, cisplatin produces ROS in kidney epithelial

\footnotetext{
${ }^{*}$ Corresponding Author: Dr. Kalpesh R. Patil

Address: Department of Pharmacology, R. C. Patel Institute of Pharmaceutical Education and Research, Karvand Naka, Shirpur-425405, District Dhule, Maharashtra, India

Email $₫$ : kalpeshpharma20@gmail.com

Tel.: +91-9850875021

Relevant conflicts of interest/financial disclosures: The authors declare that the research was conducted in the absence of any commercial or financial relationships that could be construed as a potential conflict of interest.

Copyright (C) 2020 Rachna B. Patel et al. This is an open access article distributed under the terms of the Creative Commons Attribution- NonCommercialShareAlike 4.0 International License which allows others to remix, tweak, and build upon the work non-commercially, as long as the author is credited and the new creations are licensed under the identical terms.
} 
cells and diminishes anti-oxidant enzyme activity by reducing the intracellular concentrations of GSH. ${ }^{[10,11]}$ Thus, depletion of anti-oxidant mechanisms, increased production of ROS, and renal accumulation of lipid peroxide products have been proposed as important mechanisms behind cisplatin-induced nephrotoxicity. ${ }^{[3,12]}$

Several studies have demonstrated the protective role of natural anti-oxidants against cisplatin-induced nephrotoxicity ${ }^{[13]}$ B. racemosa is a mangrove plant belongs to the Lecythidaceae family and used in traditional Indian medicine. Various parts of this plant are used in asthma, cough, control of blood pressure, and skin diseases. ${ }^{[14,15]}$ B. racemosa contains several biologically active phytoconstituents, amongst which bartogenic acid, a natural pentacyclic triterpenoid, is well known for its biological properties, including $\alpha$-glucosidase inhibitor, anti-arthritic, and anti-cancer. ${ }^{[16-18]}$ It has also been reported that various parts of $B$. racemosa exhibit many pharmacological effects, like anti-oxidant, ${ }^{[14,15,19]}$ anti-inflammatory, ${ }^{[20]}$ anti-fungal, ${ }^{[21]}$ anti-cancer, ${ }^{[22]}$ analgesic, ${ }^{[23]}$ anti-tuberculosis, ${ }^{[24]}$ and anti-diarrhoea activity. ${ }^{[25]}$ To our knowledge, there are no reports on the protective role of $B$. racemosa or bartogenic acid against anti-cancer drug-induced nephrotoxicity. Therefore, the present study was undertaken to evaluate the nephroprotective effect of bartogenic acid containing fraction of $B$. racemosa fruits (BREAF) against cisplatin-induced renal toxicity in rats.

\section{MATERIALS AND METHOD}

\section{Animals}

Experimental procedures involving the use of laboratory animals were approved by the Institutional Animal Ethics Committee (IAEC) of R. C. Patel Institute of Pharmaceutical Education and Research, Shirpur, District Dhule, India (Reg. No. 651/PO/ReBi/S/02/CPCSEA) constituted under the "Prevention of Cruelty to the Animals Act, 1960." All the experiments were carried out according to the guidelines prescribed by the Committee for the Purpose of Control and Supervision of Experiments on Animals (CPCSEA), Government of India. Healthy Sprague Dawley rats of either sex (180-230 grams) were used in the present study. Rats were housed in polypropylene cages under the standard laboratory condition at $22 \pm 2^{\circ} \mathrm{C}$, and 12 hours (light:dark) cycle with free access to water, and commercially available standard pellet feed (Nutrimix Std-1020) obtained from Nutrivet Life Sciences, Pune, India.

\section{Plant Material}

B. racemosa Roxb. (Lecythidaceae) fruits, collected from the sea coast of Maharashtra, were purchased from the local vendor. The specimen was authenticated by the taxonomist, and the specimen was deposited for future reference. An authentic marker of bartogenic acid was supplied by
Dr. Mangala Gowri, Senior Scientist, Indian Institute of Chemical Technology, Hyderabad, Telangana, India.

\section{Extraction and Isolation of BREAF}

The BREAF was isolated according to the earlier reported methods with some modification. ${ }^{[16,20]}$ Briefly, the dried and powdered fruits of $B$. racemosa were defatted with petroleum ether, followed by cold maceration with methanol at room temperature for 3 days. The methanol extract was subsequently fractionated using ethyl acetate. Ethyl acetate extract was loaded on silica gel column $(3 \times 90 \mathrm{~cm})$, using ethyl acetate as mobile phase. Elution was monitore by thin-layer chromatography (TLC) of each fraction using methanol as a solvent. The fractions having similar TLC patterns were combined to get a triterpenoids enriched fraction called BREAF. Part of this fraction (BREAF) was subjected to chromatography on pre-coated reverse-phase silica gel plate (Merck) using acetonitrile:water $(85: 15 \mathrm{v} / \mathrm{v})$ as eluent. High-performance thin-layer chromatography (HPTLC) of fraction revealed three spots, including one blue spot $\left(R_{\mathrm{f}}=0.68\right)$ approaching to bartogenic acid marker. The composition of BREAF was confirmed by liquid chromatography-electrospray ionization-mass spectrometry (LC-ESI-MS) analysis, as described previously. ${ }^{[20]}$

\section{Chemicals}

Cisplatin (CAS Number: 15663-27-1) were purchased from Sigma Aldrich, USA. Creatinine kit, urea/ blood urea nitrogen (BUN) kit, albumin kit, and protein kit were obtained from Accurex Biomedical Pvt. Ltd., Mumbai, Agappe Diagnostics Ltd., Mumbai, Beacon Diagnostic Pvt. Ltd., Navsari, India, and Span Diagnostic Ltd., Surat, India, respectively. 5-5-dithio bis-(2-nitrobenzoic acid) and thiobarbituric acid were purchased from Loba Chemie Pvt. Ltd., Mumbai, India. Other chemicals and solvents used in the fractionation and chromatographic separations were of analy tical grade.

\section{Experimental Protocol}

Rats were randomly divided into five groups, each consisting of six animals $(\mathrm{n}=6)$. Group I (normal): control group of rats received single dose of $1 \mathrm{~mL}$ saline i.p. and tween-80 solution p.o. for 5 days. Group II: cisplatin control group of animals was treated with single dose of cisplatin $5 \mathrm{mg} / \mathrm{kg}$ i.p. and tween-80 solution p.o. for 5 days. Group III: cisplatin + BREAF (2) group of rats received single dose of cisplatin $5 \mathrm{mg} / \mathrm{kg}$ i.p. and BREAF ( $2 \mathrm{mg} / \mathrm{kg}$ p.o.) for 5 days. Group IV: cisplatin + BREAF (5) group of animals received single dose of cisplatin $5 \mathrm{mg} / \mathrm{kg}$ i.p. and BREAF (5 mg/kg p.o.) for 5 days. Group V: cisplatin + BREAF (10) group of rats received single dose of cisplatin $5 \mathrm{mg} / \mathrm{kg}$ i.p. and BREAF (10 mg/kg p.o.) for 5 days.

The BREAF was dissolved in tween-80, and administered orally at the dosage of 2,5 , and $10 \mathrm{mg} / \mathrm{kg}$ 
to respective groups for 5 days. On the fourth day, animals were kept in metabolic cages for urine collection. Prior to urine collection, blood sample was collected through retro-orbital puncture, and serum was separated. On the 5th day, animals were sacrificed by an overdose of anesthetics, and the spleen, thymus, and kidney were isolated for biochemical estimation and histopathology study. The dosage of BREAF (2, 5, and $10 \mathrm{mg} / \mathrm{kg} \mathrm{p.o.)}$ were selected based on our preliminary experiments and other earlier reports estimating no toxicity even at higher dosages. ${ }^{[20]}$ The dose of cisplatin (5 mg/kg i.p.) was selected according to earlier studies that demonstrated significant nephrotoxicity in rats.

\section{Observational Parameter}

Body weight of rats was recorded before the administration of cisplatin and at the end of the experiment. Percentage (\%) change in body weight was calculated. After scarification of rats on the 5th day, the organs like kidney, spleen, and thymus were harvested, and weighed immediately after the isolation.

\section{Biochemical Estimations}

At the termination of the experiment, blood samples were analyzed for markers of renal function. Creatinine, albumin, alkaline phosphatase (ALP), and BUN levels were estimated using commercially available kits and according to the manufacturer's instructions. Creatinine estimation was done by using alkaline picrate method. Albumin was estimated by using bromocresol green method. Determination of albumin in serum is based on a binding behavior of albumin with $3^{\prime}, 3^{\prime}, 5^{\prime}, 5^{\prime}$-tetrabromo$\mathrm{m}$-cresol-sulfonephthalein in acidic medium ( $\mathrm{pH} 4.2$ ). Alkaline phosphates were estimated by p-nitrophenyl phosphate method. Urea and urea nitrogen estimation was done by using urease/ glutamate dehydrogenase method. This method is based on the preliminary hydrolysis of urease, followed by analytical processes that quantities the ammonium ion. ${ }^{[3,26-28]}$

\section{Oxidative Stress Parameter}

\section{Preparation of Renal Homogenate}

Immediately after the scarification, the kidney from each rat was dissected, rinsed with isotonic saline, and weighed. Kidney tissue was minced, and the homogenate was prepared with $10 \%(\mathrm{w} / \mathrm{v})$ phosphate-buffered saline (0.1 mol/L, pH 7.4) using a homogenizer. Homogenate was used to estimate MDA and reduced GSH.

\section{Determination of Lipid Peroxidation (LPO)}

The LPO was measured as MDA content, according to the earlier method. ${ }^{[29]}$ Briefly, the assay mixture containing $0.5 \mathrm{~mL}$ homogenate and $3 \mathrm{~mL}$ of thiobarbituric acid $(0.6 \% \mathrm{w} / \mathrm{v})$ was heated in boiling water bath for 45 minutes. Subsequently, the mixture was cooled immediately in ice bath, and $4 \mathrm{~mL}$ of $\mathrm{n}$-butanol was added to the mixture. It was vortex and centrifuged at 5,000 rpm for 10 minutes. Absorbance of organic layer was recorded at $535 \mathrm{~nm}$, and results were expressed as a percentage of control.

\section{Determination of Reduced GSH}

Reduced GSH in the kidney tissue was estimated according to the previous method with some modifications. ${ }^{[30]}$ The homogenate $(0.75 \mathrm{~mL})$ was precipitated with $4 \%$ sulfosalicylic acid $(0.75 \mathrm{~mL})$. Sample was centrifuged at 1,200 grams for 15 minutes at $4^{\circ} \mathrm{C}$. The assay mixture consisted of $0.5 \mathrm{~mL}$ supernatant and $4.5 \mathrm{~mL}$ of $0.001 \mathrm{~mol} / \mathrm{L}$ of 5-5-dithio bis-(2-nitrobenzoic acid) (in $0.1 \mathrm{~mol} / \mathrm{L}$ phosphate buffer, pH 8.0). The yellow color developed was read immediately at $412 \mathrm{~nm}$, using a microplate reader (BioTek, USA). ${ }^{[31]}$

\section{Determination of SOD}

The SOD is estimated by the reported method. ${ }^{[32]}$ Briefly, the reaction mixture containing $100 \mu \mathrm{L}$ of each of the $500 \mathrm{mM} / \mathrm{L}$ of $\mathrm{Na}_{2} \mathrm{CO}_{3}, 1 \mathrm{mM} / \mathrm{L}$ of ethylenediaminetetraacetic acid (EDTA), $240 \mu \mathrm{M} / \mathrm{L}$ of nitro blue tetrazolium (NBT), $0.3 \%$ trion X-100, $25 \mu \mathrm{L}$ of $10 \mathrm{mM} / \mathrm{L}$ of hydroxylamine and $25 \mu \mathrm{L}$ of the sample was thoroughly mixed. The absorbance was recorded at $560 \mathrm{~nm}$ at 30 seconds and 210 seconds. $^{[33]}$

\section{Determination of Catalase Activity}

Catalase activity was assayed according to the method of Luck, ${ }^{[34]}$ in which the breakdown of hydrogen peroxide is measured at $240 \mathrm{~nm}$. Briefly, the assay mixture consisted of $3 \mathrm{~mL}$ of hydrogen peroxide phosphate buffer $\left(1.25 \times 10^{-2} \mathrm{H}_{2} \mathrm{O}_{2} \mathrm{~mol}\right)$ and $0.05 \mathrm{~mL}$ supernatant of kidney homogenate (10\%). The change in absorbance was recorded at $240 \mathrm{~nm}$ using microplate reader. Enzyme activity was calculated using the millimolar coefficient of $\mathrm{H}_{2} \mathrm{O}_{2}$. ${ }^{[35]}$

\section{Histopathological Analysis}

At the end of the experiment, animals were sacrificed after the 24 hours urine collection. Paraformaldehydefixed kidney tissues were dehydrated in ascending graded series of alcohol and embedded in paraffin. Kidney tissue specimens were cut into slices of $5 \mu \mathrm{m}$ thickness using microtome, followed by staining with hematoxylin and eosin, according to routine staining protocols. The histological sections were examined with a light microscope. ${ }^{[3,13]}$

\section{Statistical Analysis}

Results are expressed as mean \pm SEM, and statistical significance of difference in the central tendencies of treatment groups was determined by one-way ANOVA followed by Dunnett's multiple comparison test. $\mathrm{p}<0.05$ was considered statistically significant. 


\section{RESULTS}

\section{BREAF contains Bartogenic Acid}

The BREAF on HPTLC showed an intense blue spot $\left(R_{f}=0.68\right)$ matching with bartogenic acid marker. LC-ESI-MS analysis showed molecular ion peak at $\mathrm{m} / \mathrm{z} 517.5[\mathrm{M}-\mathrm{H}]^{-}$, corresponding to molecular formula $\mathrm{C}_{30} \mathrm{H}_{46} \mathrm{O}_{7}$, which is in congruence with previously available data of bartogenic acid. ${ }^{[20]}$ HPTLC and LC-ESI-MS analysis revealed that the chief constituent of BREAF was bartogenic acid. ${ }^{[20]}$

\section{BREAF significantly altered the Body and Organ Weights in Treated Animals}

Single intraperitoneal injection of cisplatin $(5 \mathrm{mg} / \mathrm{kg})$ caused the notable weight loss in the cisplatin-control group as compared with the normal control group on 5 th day $(p<0.001)$. However, these changes were significantly $(\mathrm{p}<0.001)$ prevented by BREAF at the dosage of 2, 5, and $10 \mathrm{mg} / \mathrm{kg}$, p.o. (Fig. 1A). The relative kidney, spleen, and thymus weights in $\operatorname{BREAF}(2,5$, and $10 \mathrm{mg} / \mathrm{kg}$, p.o.) treated animals were significantly ( $p<0.001)$ reduced as compared with organ weights of animals in cisplatin-control group (Figs $1 \mathrm{~A}$ to $\mathrm{D}$ ).

\section{BREAF demonstrated favorable Effects on Renal Functions}

Serum creatinine and BUN levels were measured in all the animals to evaluate the protective effect of BREAF on renal function. Elevated levels of creatinine and BUN indicate acute nephrotoxicity. However, elevated alkaline phosphate is the hallmark of organ toxicity. Following injection of cisplatin ( $5 \mathrm{mg} / \mathrm{kg}$ i.p.), the serum levels of creatinine, BUN, and alkaline phosphate were found to increase significantly ( $p<0.001)$, as compared
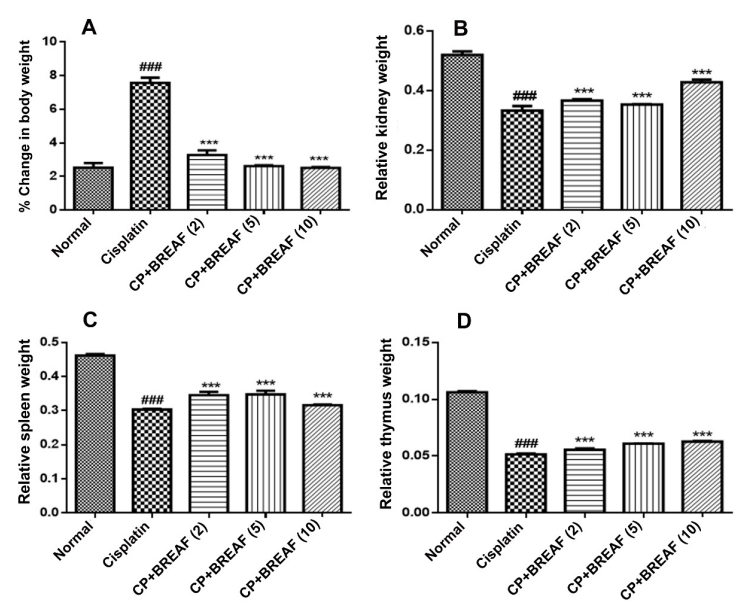

Fig. 1: Effect of BREAF on body weight changes and relative organ weight in cisplatin-induced nephrotoxicity in rats; A) \% change in body weight; B) Relative kidney weight; C) Relative spleen weight; D) Relative thymus weight; values represent mean \pm SEM $(n=6)$ animals per group; ${ }^{\# \# \# ~}<0.001$ as compared with normal group; ${ }^{* * *} \mathrm{p}<0.001$ as compared with control group (one-way ANOVA followed by Dunnett's multiple comparison post hoc test) with normal-control group, suggesting severe kidney damage following cisplatin injection (Figs $2 \mathrm{~A}$ to D). Administration of BREAF (2, 5, and $10 \mathrm{mg} / \mathrm{kg}$ p.o.) to animals exerted significant $(\mathrm{p}<0.001)$ nephroprotective effect, as evidenced by decreased levels of creatinine and BUN, as compared to cisplatin control group (Figs 2A and B). The four-fold increase in alkaline phosphate was observed in cisplatin-control group, as compared to normal-control group. In the present study, BREAF showed significant $(p<0.001)$ and dose-dependent decrease in serum alkaline phosphate levels and non dose-dependent increase in albumin level as compared to cisplatin-control group (Figs 2C and D).

\section{BREAF diminished Cisplatin-Induced Oxidative Stress}

Single-dose administration of cisplatin resulted in the notable increase of MDA content along with significant ( $p<0.001)$ decrease in GHS, SOD, and catalase content as compared with normal-control group (Figs 3A to D). Alternatively, treatment of animals with BREAF at the dosage of 2, 5, and $10 \mathrm{mg} / \mathrm{kg}$ p.o. for 5 days resulted in significant $(p<0.001)$ increase in GHS, SOD, and catalase level along with significant $(p<0.001)$ decrease in MDA level. The effect of BREAF on SOD level was in dose-dependent manner; however, the effect of BREAF on GHS, catalase, and MDA was found to be non-dose dependent (Figs 3A to D).

\section{BREAF attenuated Cisplatin-Induced Renal Histopathological Changes in Rats}

Histopathological study of kidney tissues in normal rats demonstrated the normal appearance of renal tubules. The kidney tissues in cisplatin exposed group showed necrosis
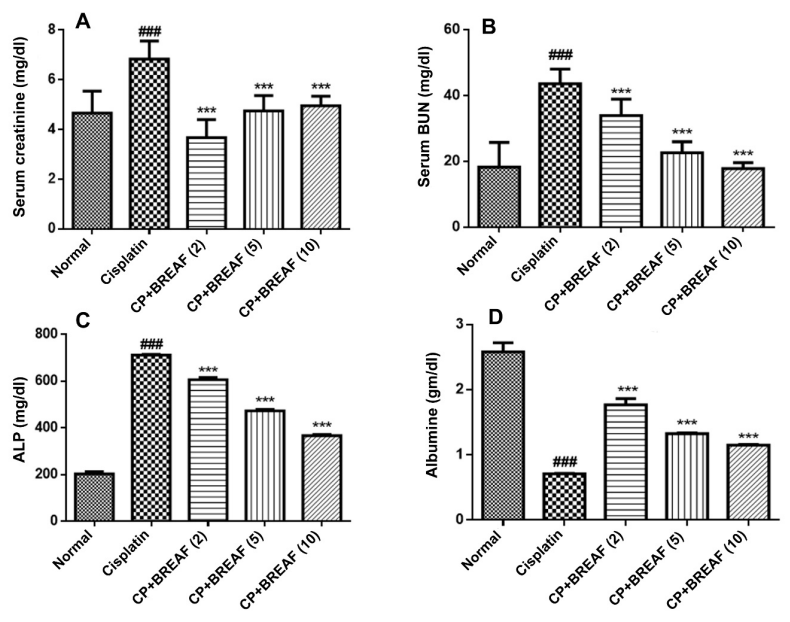

Fig. 2: Effect of BREAF on biomarkers of kidney function in cisplatininduced nephrotoxicity in rats; A) Serum creatinine $(\mathrm{mg} / \mathrm{dL}$ ); B) Serum BUN (mg/dL); C) ALP (mg/dL); D) Albumin (gm/dL); values represent mean \pm SEM $(n=6)$ animals per group; ${ }^{\# \# \# ~} p<0.001$ as compared with normal group; ${ }^{* * *} \mathrm{p}<0.001$ as compared with control group (one-way ANOVA followed by Dunnett's multiple comparison post hoc test) 

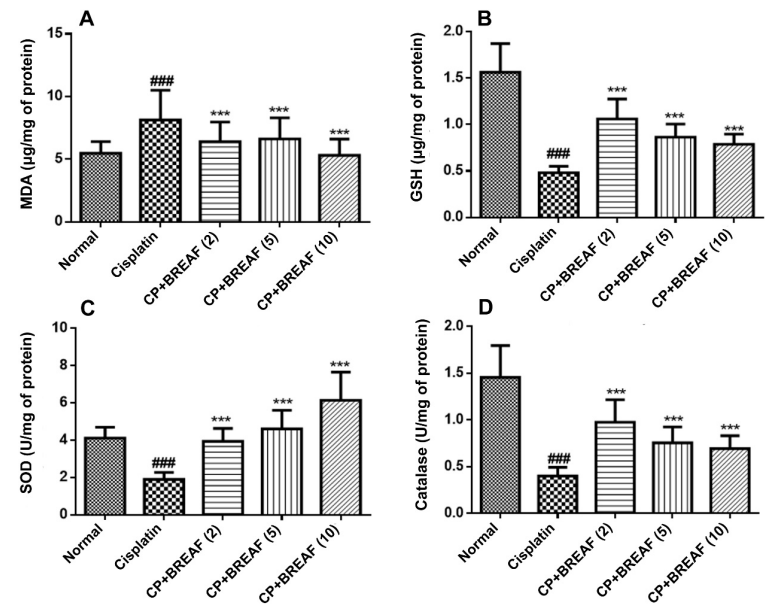

Fig. 3: Effect of BREAF on oxidative stress parameters in cisplatininduced nephrotoxicity in rats; A) MDA ( $\mu \mathrm{g} / \mathrm{mg}$ of protein); B) $\mathrm{GSH}(\mu \mathrm{g} / \mathrm{mg}$ of protein); C) SOD (U/mg of protein); D) Catalase $(\mathrm{U} / \mathrm{mg}$ of protein); values represent mean \pm SEM $(n=6)$ animals per

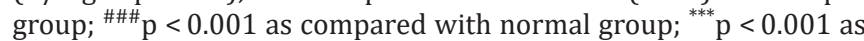
compared with control group (one-way ANOVA followed by Dunnett's multiple comparison post hoc test)

of renal tubules, cast formation, interstitial leukocyte infiltration, and congestion of inter-tubular blood vessels indicating the kidney damage (Fig. 4). Group treated with low and middle ( 2 and $5 \mathrm{mg} / \mathrm{kg}$ p.o.) dose of BREAF showed evidence for the necrosis of renal tubules, presence of cast, and leucocyte infiltration. But, the group treated with high dose of BREAF (10 mg/kg p.o.) normalized the cisplatininduced histopathological changes, and decreased the infiltration of inflammatory cells. These observations reinforce the earlier results of the anti-inflammatory action of BREAF. ${ }^{[20]}$

\section{Discussion}

Cisplatin is effective chemotherapeutic agent used for the treatment of several cancers. Despite its anti-cancer potential, the use of cisplatin is associated with severe side effects, especially nephrotoxicity. ${ }^{[3,29]}$ There is a lack of drugs that can offer protection to the kidneys against cisplatin-induced toxicity, and search for the nephroprotective drugs is continuing. Several studies have been conducted to enhance our understanding of the pathogenesis and treatment of cisplatin-induced nephrotoxicity. ${ }^{[36]}$ Pathophysiology of cisplatin-induced tubular damage is complex, which shows the involvement of many interconnected factors. The mechanisms of cisplatininduced nephrotoxicity may involve accumulation of cisplatin in renal tubules, conversion of cisplatin into nephrotoxins, mitochondrial dysfunction, and DNA damage. ${ }^{[3,12]}$ Additional mechanisms include, oxidative stress, inflammation, and fibrogenesis along with activation of the apoptotic pathway through the activation of cell cycle arrest, disturbance of renal tubular cell transport systems, and alterations in ATPase activity. ${ }^{[37-39]}$

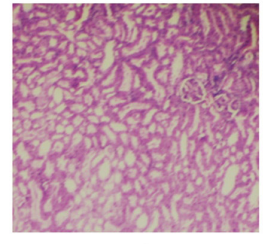

Normal
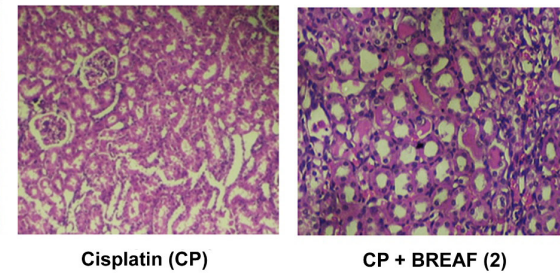

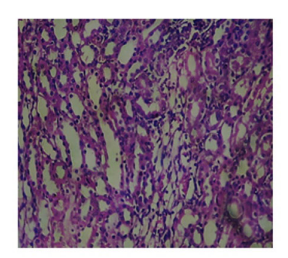

CP + BREAF (5)

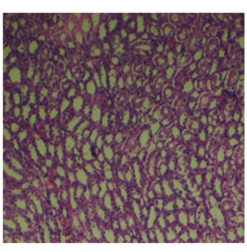

CP + BREAF (10)
Fig. 4: Effect of BREAF on histopathological changes in kidney tissues in cisplatin-induced nephrotoxicity in rats; Kidney tissue specimens were cut into slices of $5 \mu \mathrm{m}$ thickness, followed by staining with hematoxylin and eosin, according to routine staining protocols;

Microscopic examination was carried out under light microscopy

The various parts of B. racemosa are reported to possess biological activities, like anti-bacterial, anti-fungal, anti-oxidant, analgesic, anti-inflammatory, anti-arthritic, and anti-diarrhoeal activity. ${ }^{[17,21,23,25,40,41]}$ The present study was conducted to evaluate the protective effect of BREAF in cisplatin-induced nephrotoxicity in rats. We observed that BREAF decreased cisplatin-induced nephrotoxicity through the minimization of renal tubular damage, body weight changes, oxidative stress, and inflammation. Intraperitoneal administration of cisplatin resulted in augmented oxidative stress through increase in MDA and decrease in anti-oxidant enzymes, as well as, increased creatinine and BUN levels, suggesting the induction of nephrotoxicity in cisplatin exposed rats. Results demonstrated that oral treatment of animals with BREAF at the dosage of 2,5 , and $10 \mathrm{mg} / \mathrm{kg}$ had nephroprotective effect as evident through observational, biochemical, and histopathological investigations in cisplatin and BREAF treated animals.

In the present study, the rats treated with cisplatin showed a decrease in total body weight along with a decrease in relative kidney, thymus, and spleen weights. The oral treatment of rats with $\operatorname{BREAF}(2,5$, and $10 \mathrm{mg} / \mathrm{kg}$ ) showed significant recovery from cisplatininduced total body weight and organ weight loss. The cisplatin-induced decrease in weight loss could be due to reduced food intake by the animals and gastrointestinal toxicity ${ }^{[42,43]}$ Creatinine and urea are the major biomarkers of nephrotoxicity, and their level significantly increases in nephrotoxicity. Increase in serum creatinine and BUN levels in cisplatin-treated rats, which occurred due to glomerular and renal tubal damage, is well established through several studies. ${ }^{[13,26,44,45]}$ Serum creatinine is easily measurable and important indicator of renal function. Creatinine is mainly filtered through the kidneys and any injury to kidney that leads to an increase in serum creatinine 
level. ${ }^{[10]}$ Administration of cisplatin at single-dose causes acute renal failure ${ }^{[10]}$ The peak creatinine level following cisplatin administration is reported on the 5th day of cisplatin injection. Increased serum creatinine represents irreversible renal tubular injury, and it is the indirect measure of glomerular filtration rate. ${ }^{[10,46]}$ Serum urea level, usually referred to as BUN, is also used to determine renal function. Ammonia formed during the protein metabolism is transformed into urea, which is excreted through the kidney. Renal dysfunction leads to decrease in the elimination of urea that causes accumulation of urea in the bloodstream. ${ }^{[10,46]}$ BREAF administration offered protection through the improvement of renal function as revealed by a notable decrease in serum creatinine and BUN in comparison with the cisplatin-control group. ALP is an important biomarker of kidney damage. The ALP level is increase in pathological conditions, especially liver and kidney diseases. In the present study, treatment of animals with BREAF resulted in a decreased level of ALP.

Oxidative stress is a major factor contributing to acute renal failure ${ }^{[47]}$ Usually, the endogenous anti-oxidants, like SOD, GSH, and catalase detoxifies the ROS produced during the course of normal cellular processes. However, the administration of cisplatin causes excessive accumulation of ROS, leading to increased lipid peroxidation and endogenous anti-oxidant depletion. ${ }^{[48,49]}$ Increased MDA level following cisplatin administration indicate the enhanced LPO due to deleterious effect of ROS on cell membrane lipids. Excessive accumulation of MDA in kidney tissues leads to overutilization and subsequent depletion of anti-oxidant enzymes, including GSH. ${ }^{[50,51]}$ The notable decrease in the activity of anti-oxidant enzymes in the present study may occur due to increased activity of NADPH oxidase and xanthine oxidase, which causes subsequent depletion of anti-oxidant enzymes (catalase and SOD), GSH, and enhancement of MDA in kidney tissues. ${ }^{[48,52]}$

GSH is essential anti-oxidant tripeptide for the maintenance of cellular integrity and cell metabolism. ${ }^{[53]}$ Oxidative stress caused by cisplatin treatment in rats has been reported to deplete the GSH levels in kidney tissues. ${ }^{[54,55]}$ A decrease in GSH levels following treatment of animals with cisplatin can be attributed to its utilization in the detoxification of toxicants and regulation of cellular homeostasis. ${ }^{[56]} \mathrm{GSH}$ offers protection against potential nephrotoxicity through the formation of GSH adducts. ${ }^{[57]}$ ROS scavenging by GSH may involve various enzymatic and non-enzymatic mechanisms. Lipid peroxidation after cisplatin administration is attributed to the depletion of GSH and impaired anti-oxidant enzyme activity. Treatment of animals with BREAF $(2,5$, and $10 \mathrm{mg} / \mathrm{kg}$ p.o.) resulted in an increased level of GSH as compared with cisplatin-control group. This effect of BREAF on GSH levels may involve its direct anti-oxidant effects, increased biosynthesis of GSH, or enhanced levels of other anti-oxidants. ${ }^{[43,58]}$
Superoxide is highly reactive, and cytotoxic ROS produced during oxygen metabolism. The SOD has an important role in the conversion of toxic superoxide into the less toxic hydrogen peroxide. SOD is the first line of defense against ROS-mediated tissue injuries. ${ }^{[4]}$ In the present study, level of SOD was decreased in cisplatin-control group, as compared to the normal-control group, which may occur due to exhaustion of zinc and copper that are essential for the activity of anti-oxidant enzymes. ${ }^{[10,59]}$ Whereas, the treatment of animals with BREAF at 2, 5, and $10 \mathrm{mg} / \mathrm{kg}$ p.o., resulted in an increased level of SOD in renal tissues. Catalase is an enzyme that catalyzes the conversion of hydrogen peroxide to water and oxygen. ${ }^{[60]}$ Catalase offers protection against several ROS-mediated toxicities, including cisplatin-induced nephrotoxicity. ${ }^{[10,61]}$ Treatment of animals with BREAF at all the tested dosages showed significant increase in catalase level. It signifies the anti-oxidant activity of BREAF during cisplatin-induced kidney toxicity. Overall results of this study demonstrate that BREAF caused a decrease in oxidative stress and an increase in anti-oxidant enzymes. These results of BREAF are in agreement with previous studies reporting the anti-oxidant potential of $B$. racemosa. ${ }^{[14,15,19]}$

Histopathological observation also showed that BREAF decreased the tissue necrosis, interstitial edema, and inflammatory cell infiltration caused by cisplatin. This study substantiates that intraperitoneal injection of cisplatin at the dose of $5 \mathrm{mg} / \mathrm{kg}$ in single-dose induced severe nephrotoxicity in rats. BREAF ameliorated cisplatin-induced nephrotoxicity at the minute dosage of 2, 5, and $10 \mathrm{mg} / \mathrm{kg}$ p.o. The nephroprotective effect of BREAF involves the anti-oxidant mechanisms, and this activity of BREAF is attributed to its bartogenic acid content.

In conclusion, bartogenic acid is a pentacyclic triterpenoid present in the fruits of $B$. racemosa. It was reported to possess the anti-cancer activity in DMBA-croton oil-induced two-stage carcinogenesis model in mice. The present study highlights the nephroprotective activity of BREAF against cisplatin-induced nephrotoxicity in rats. The anti-cancer and nephroprotective activities of BREAF can facilitate the activities of various chemotherapeutic drugs and offer protection against cisplatin-induced nephrotoxicity. Therefore, BREAF could be a suitable adjuvant to anti-cancer chemotherapy.

\section{ACKNOWLEDGEMENTS}

Authors are thankful to Dr. P. Mangala Gowri, Indian Institute of Chemical Technology, Hyderabad (India), for providing the sample of bartogenic acid.

\section{REFERENCES}

1. Delord J-P, Puozzo C, Lefresne F, Bugat R. Combination chemotherapy of vinorelbine and cisplatin: a phase I pharmacokinetic study in patients with metastatic solid tumors. Anti-cancer Research. 2009;29(2):553-560. 
2. Somani SM, Husain K, Whitworth C, Trammell GL, Malafa M, Rybak LP. Dose-dependent protection by lipoic acid against cisplatin-induced nephrotoxicity in rats: antioxidant defense system. Basic and Clinical Pharmacology and Toxicology. 2000;86(5):234-241.

3. IlićS, Stojiljković N, Veljković M, VeljkovićS, Stojanović G. Protective effect of quercetin on cisplatin-induced nephrotoxicity in rats. Facta Universitatis, Series: Medicine and Biology. 2014;16(2):71-75.

4. Mohan IK, Khan M, Shobha JC, Naidu MUR, Prayag A, Kuppusamy P, et al. Protection against cisplatin-induced nephrotoxicity by Spirulina in rats. Cancer Chemotherapy and Pharmacology. 2006;58(6):802. https://doi.org/10.1007/s00280-006-0231-8

5. Gao L, Wu W-F, Dong L, Ren G-L, Li H-D, Yang Q, et al. Protocatechuic aldehyde attenuates cisplatin-induced acute kidney injury by suppressing nox-mediated oxidative stress and renal inflammation. Frontiers in Pharmacology. 2016;7:479. DOI: $10.3389 /$ fphar.2016.00479

6. Heidemann HT, Müller S, Mertins L, Stepan G, Hoffmann K, Ohnhaus E. Effect of aminophylline on cisplatin nephrotoxicity in the rat. British Journal of Pharmacology. 1989;97(2):313-318.

7. Miller RP, Tadagavadi RK, Ramesh G, Reeves WB. Mechanisms of cisplatin nephrotoxicity. Toxins. 2010;2(11):2490-2518.

8. Safirstein R, Winston J, Moel D, Dikman S, Guttenplan J. Cisplatin nephrotoxicity: insights into mechanism. International Journal of Andrology. 1987;10(1):325-346.

9. Xiao T, Choudhary S, Zhang W, Ansari N, Salahudeen A. Possible involvement of oxidative stress in cisplatin-induced apoptosis in LLC-PK1 cells. Journal of Toxicology and Environmental Health Part A. 2003;66(5):469-479.

10. Prabhu VV, Kannan N, Guruvayoorappan C. 1, 2-Diazole prevents cisplatin-induced nephrotoxicity in experimental rats. Pharmacological Reports. 2013;65(4):980-990.

11. Bhat SG, Mishra S, Mei Y, Nie Z, Whitworth CA, Rybak LP, et al. cisplatin up-regulates the adenosine $\mathrm{A} 1$ receptor in the rat kidney. European Journal of Pharmacology. 2002;442(3):251-264.

12. Peres LAB, Cunha Júnior ADd. Acute nephrotoxicity of cisplatin: molecular mechanisms. Jornal Brasileiro de Nefrologia. 2013;35(4):332-340.

13. Sherif IO. Amelioration of cisplatin-induced nephrotoxicity in rats by triterpenoid saponin of Terminalia arjuna. Clinical and Experimental Nephrology. 2015;19(4):591-597.

14. Ali AM, Muse R, Mohd NB. Anti-oxidant and anti-inflammatory activities of leaves of Barringtonia racemosa. Journal of Medicinal Plants Research. 2007;1(5):95-102.

15. Kong KW, Aziz AA, Razali N, Aminuddin N, Junit SM. Antioxidantrich leaf extract of Barringtonia racemosa significantly alters the in vitro expression of genes encoding enzymes that are involved in methylglyoxal degradation III. PeerJ. 2016;4:e2379.

16. Gowri PM, Tiwari AK, Ali AZ, Rao JM. Inhibition of $\alpha$-glucosidase and amylase by bartogenic acid isolated from Barringtonia racemosa Roxb. seeds. Phytotherapy Research. 2007;21(8):796-799.

17. Patil KR, Patil CR, Jadhav RB, Mahajan VK, Patil PR, Gaikwad PS. Anti-arthritic activity of bartogenic acid isolated from fruits of Barringtonia racemosa Roxb. (Lecythidaceae). Evidence-Based Complementary and Alternative Medicine. 2011;2011:785245. DOI: $10.1093 /$ ecam/nep148

18. Patil CR, Sonara BM, Mahajan UB, Patil KR, Patil DD, Jadhav RB, et al. Chemomodulatory potential of bartogenic acid against DMBA/ croton oil induced two-step skin carcinogenesis in mice. Journal of Cancer. 2016;7(14):2139.

19. Nurul MH, Radzali M, Johari R, Syahida A, Maziah M. Antioxidant activities of different aerial parts of putat (Barringtonia racemosa L.). Malaysian Journal of Biochemistry and Molecular Biology. 2008;16(2):15-19.

20. Patil KR, Patil CR. Anti-inflammatory activity of bartogenic acid containing fraction of fruits of Barringtonia racemosa Roxb. in acute and chronic animal models of inflammation. Journal of Traditional and Complementary Medicine. 2017;7(1):86-93.

21. Hussin N, Muse R, Ahmad S, RamLi J, Mahmood M, Sulaiman M, et al. Antifungal activity of extracts and phenolic compounds from Barringtonia racemosa L. (Lecythidaceae). African Journal of Biotechnology. 2009;8(12):2835-2842.

22. Thomas TJ, Panikkar B, Subramoniam A, Nair MK, Panikkar K. Antitumour property and toxicity of Barringtonia racemosa Roxb seed extract in mice. Journal of Ethnopharmacology. 2002;82(2-3): 223-227.

23. Deraniyagala S, Ratnasooriya W, Goonasekara C. Antinociceptive effect and toxicological study of the aqueous bark extract of Barringtonia racemosa on rats. Journal of Ethnopharmacology. 2003;86(1):21-26.

24. Mmushi T, Masoko P, Mde L, Mokgotho M, Mampuru L, Howard R. Antimycobacterial evaluation of fifteen medicinal plants in South Africa. African Journal of Traditional, Complementary and Alternative Medicines. 2010;7(1): 34-39.

25. Saha S, Sarkar KK, Hossain ML, Hossin A, Barman AK, Ahmed MI, et al. Bioactivity studies on Barringtonia racemosa (Lam.) Bark. Pharmacologyonline. 2013;1:93-100.

26. Bami E, Ozakpınar OB, Ozdemir-Kumral ZN, Köroglu K, Ercan F, Cirakli Z, et al. Protective effect of ferulic acid on cisplatininduced nephrotoxicity in rats. Environmental Toxicology and Pharmacology. 2017;54:105-111.

27. Shirwaikar A, Issac D, Malini S. Effect of Aerva lanata on cisplatin and gentamicin models of acute renal failure. Journal of Ethnopharmacology. 2004;90(1):81-86.

28. Harlalka GV, Patil CR, Patil MR. Protective effect of Kalanchoe pinnata Pers. (Crassulaceae) on gentamicin-induced nephrotoxicity in rats. Indian journal of pharmacology. 2007;39(4):201-205.

29. Li W, Yan M-H, Liu Y, Liu Z, Wang Z, Chen C, et al. Ginsenoside Rg5 ameliorates cisplatin-induced nephrotoxicity in mice through inhibition of inflammation, oxidative stress, and apoptosis. Nutrients. 2016;8(9):566. DOI: 10.3390/nu8090566.

30. Avi-Dor Y, Lipkin R. A spectrophotometric method for the determination of reduced glutathione. J Biol Chem. 1958;233(1):69-72.

31. Palipoch S, Punsawad C, Chinnapun D, Suwannalert P. Amelioration of cisplatin-induced nephrotoxicity in rats by curcumin and $\alpha$-tocopherol. Tropical Journal of Pharmaceutical Research. 2013;12(6):973-979.

32. Kono Y. Generation of superoxide radical during autoxidation of hydroxylamine and an assay for superoxide dismutase. Archives of Biochemistry and Biophysics. 1978;186(1):189-195.

33. Chao C-S, Tsai C-S, Chang Y-P, Chen J-M, Chin H-K, Yang S-C. Hyperin inhibits nuclear factor kappa B and activates nuclear factor E2-related factor-2 signaling pathways in cisplatin-induced acute kidney injury in mice. International Immunopharmacology. 2016;40:517-523.

34. Lück H. Catalase. Methods of enzymatic analysis: Elsevier; 1965. p. 885-894.

35. Arjumand W, Seth A, Sultana S. Rutin attenuates cisplatin induced renal inflammation and apoptosis by reducing NFKB, TNF- $\alpha$ and caspase-3 expression in Wistar rats. Food and Chemical Toxicology. 2011;49(9):2013-2021.

36. Malik S, Suchal K, Bhatia J, Gamad N, Dinda AK, Gupta YK, et al. Molecular mechanisms underlying attenuation of cisplatin-induced acute kidney injury by epicatechin gallate. Laboratory Investigation. 2016;96(8):853-861.

37. Razzaque MS. Cisplatin nephropathy: is cytotoxicity avoidable? Oxford University Press; 2007.

38. Yao X, Panichpisal K, Kurtzman N, Nugent K. Cisplatin nephrotoxicity: a review. The American Journal of the Medical Sciences. 2007;334(2):115-124.

39. Hosseinian S, Rad AK, Mousa-Al-Reza HNM, Roshan SH, Shafiee S. The protective effect of Nigella sativa against cisplatin-induced nephrotoxicity in rats. Avicenna Journal of Phytomedicine. 2016;6(1):44-54.

40. Khan S, Jabbar A, Hasan C, Rashid M. Antibacterial activity of Barringtonia racemosa. Fitoterapia. 2001;72(2):162-164.

41. Kong KW, Mat-Junit S, Aminudin N, Ismail A, Abdul-Aziz A. Antioxidant activities and polyphenolics from the shoots of Barringtonia racemosa (L.) Spreng in a polar to apolar medium system. Food Chemistry. 2012;134(1):324-332. 
Rachna B. Patel et al.

42. de Oliveira Mora L, Antunes LMG, Francescato HsDC, Bianchi MdLP. The effects of oral glutamine on cisplatin-induced nephrotoxicity in rats. Pharmacological Research. 2003;47(6):517-522.

43. Atessahin A, Yilmaz S, Karahan I, Ceribasi AO, Karaoglu A. Effects of lycopene against cisplatin-induced nephrotoxicity and oxidative stress in rats. Toxicology. 2005;212(2-3):116-123.

44. Helmy M, Helmy M, ALLAH D, ZAID A, El-Din M. Role of nitergic and endothelin pathways modulations in cisplatin-induced nephrotoxicity in male rats. JPP. 2014;65(3):393-399.

45. Domitrović R, Cvijanović O, Šušnić V, Katalinić N. Renoprotective mechanisms of chlorogenic acid in cisplatin-induced kidney injury. Toxicology. 2014;324:98-107.

46. Dickey DT, Muldoon LL, Doolittle ND, Peterson DR, Kraemer DF, Neuwelt EA. Effect of $\mathrm{N}$-acetylcysteine route of administration on chemoprotection against cisplatin-induced toxicity in rat models. Cancer Chemotherapy and Pharmacology. 2008;62(2):235-241.

47. Vaziri ND, Dicus M, Ho ND, Boroujerdi-Rad L, Sindhu RK. Oxidative stress and dysregulation of superoxide dismutase and NADPH oxidase in renal insufficiency. Kidney International. 2003;63(1):179-185.

48. Hassan HA, Edrees GM, El-Gamel EM, El-sayed EA. Amelioration of cisplatin-induced nephrotoxicity by grape seed extract and fish oil is mediated by lowering oxidative stress and DNA damage. Cytotechnology. 2014;66(3):419-429.

49. Kim Y-H, Kim Y-W, Oh Y-J, Back N-I, Chung S-A, Chung H-G, et al. Protective effect of the ethanol extract of the roots of Brassica rapa on cisplatin-induced nephrotoxicity in LLC-PK1 cells and rats. Biological and Pharmaceutical Bulletin. 2006;29(12):2436-2441.

50. Amirshahrokhi K, Khalili A-R. Thalidomide ameliorates cisplatininduced nephrotoxicity by inhibiting renal inflammation in an experimental model. Inflammation. 2015;38(2):476-484.

51. Al-Kahtani MA, Abdel-Moneim AM, Elmenshawy OM, El-Kersh MA. Hemin attenuates cisplatin-induced acute renal injury in male rats. Oxidative Medicine and Cellular Longevity. 2014;2014:476430.

52. Ali B, Al Moundhri M, Tag Eldin M, Nemmar A, Tanira M. The ameliorative effect of cysteine prodrug 1-2-oxothiazolidine-4carboxylic acid on cisplatin-induced nephrotoxicity in rats. Fundamental and Clinical Pharmacology. 2007;21(5):547-553.

53. Wu G, Fang Y-Z, Yang S, Lupton JR, Turner ND. Glutathione metabolism and its implications for health. The Journal of Nutrition. 2004;134(3):489-492.

54. Silva CR, Antunes LMG, Maria de Lourdes PB. Anti-oxidant action of bixin against cisplatin-induced chromosome aberrations and lipid peroxidation in rats. Pharmacological Research. 2001;43(6):561-566.

55. Afifi ME. Effect of camel's milk on cisplatin-induced nephrotoxicity in Swiss Albino mice. Am J Biochem Biotechnol. 2010;6(141):147. DOI: $10.3844 /$ ajbbsp.2010.141.147.

56. Wu YJ, Muldoon LL, Neuwelt EA. The chemoprotective agent $\mathrm{N}$-acetylcysteine blocks cisplatin-induced apoptosis through caspase signaling pathway. Journal of Pharmacology and Experimental Therapeutics. 2005;312(2):424-431.

57. Ognjanović BI, Djordjević NZ, Matić MM, Obradović JM, MLadenović JM, Štajn AS̆, et al. Lipid peroxidative damage on cisplatin exposure and alterations in anti-oxidant defense system in rat kidneys: a possible protective effect of selenium. International Journal of Molecular Sciences. 2012;13(2):1790-1803.

58. Kim YK, Jung JS, Lee SH, Kim YW. Effects of anti-oxidants and $\mathrm{Ca}^{2+}$ in cisplatin-induced cell injury in rabbit renal cortical slices. Toxicology and Applied Pharmacology. 1997;146(2):261-269.

59. Badary OA, Abdel-Maksoud S, Ahmed WA, Owieda GH. Naringenin attenuates cisplatin nephrotoxicity in rats. Life Sciences. 2005;76(18):2125-2135.

60. Chirino YI, Hernández-Pando R, Pedraza-Chaverrí J. Peroxynitrite decomposition catalyst ameliorates renal damage and protein nitration in cisplatin-induced nephrotoxicity in rats. BMC Pharmacology. 2004;4(1):20. DOI: 10.1186/1471-2210-4-20

61. Ma S-F, Nishikawa M, Hyoudou K, Takahashi R, Ikemura M, Kobayashi $Y$, et al. Combining cisplatin with cationized catalase decreases nephrotoxicity while improving antitumor activity. Kidney International. 2007;72(12):1474-1482.

HOW TO CITE THIS ARTICLE: Patel RB, Mahajan UB, Goyal SN, Surana SJ, Patil CR, Patil KR. Protective effect of Barringtonia racemosa ethyl acetate fraction against cisplatin-induced nephrotoxicity in rats. Int. J. Pharm. Sci. Drug Res. 2020;12(4):396-403. DOI: 10.25004/IJPSDR.2020.120413 